\title{
Journalism Education, Practice and Gender Issues in Nigeria: Factors Determining Journalism Career Consideration by Female Graduates of Mass Communication
}

\author{
Adamkolo Mohammed Ibrahim* \\ Lecturer, Department of Mass Communication, \\ University of Maiduguri, Borno State, Nigeria; \\ $\mathrm{PhD}$ student, Bayero University, Kano, Nigeria; \\ Lecturer and Coordinator, Mass Communication Diploma Programme, \\ Yobe State University, PMB 1144, KM 7 Gujba Road, Damaturu, Yobe State, Nigeria \\ Maryam Maina Wagami \\ Department of Mass Communication, University of Maiduguri, Borno State, Nigeria \\ Abubakar Sufyanu Saidu Al-Sadique \\ $\mathrm{PhD}$ Research Candidate, Department of Mass Communication, \\ Bayero University, Kano, PMB 3011 Kano, Kano State, Nigeria; \\ Research Scholar, Department of Mass Communication, \\ The Federal Polytechnic, Bauchi, Bauchi State, Nigeria \\ Ahmed Lawal Gusau \\ Department of Mass Communication, \\ Abdu Gusau Polytechnic, Talata Mafara, Zamfara State, Nigeria \\ Mohammed Nura Nguru \\ Lecturer, Mass Communication from the Information Unit, \\ Office of the Rector, the Federal Polytechnic, Damaturu, P.M.B.1006 Damaturu, Yobe State, Nigeria
}

The research was self-financed.

\section{Abstract}

Over the past two to three decades, journalism education at advanced levels is increasingly gaining popular acceptance despite being gendered, with more institutions of higher learning (such as universities and polytechnics) offering courses in Mass Communication and Journalism across Nigeria. Also, since the deregulation of the Nigerian broadcast media industry in 1992, many public and commercial broadcast outlets have been established across Nigeria, thus providing a bustling market for journalism career. This development could have encouraged those who studied Mass Communication and Journalism especially women (who are often discriminated against) to consider adopting journalism as a career after graduation. However, it is not known whether that is obtainable, and what factors could be affecting that. To solve that research gap, this study examined the factors impeding the adoption of journalism as a career among female graduates of mass communication in Maiduguri, Borno State, Nigeria. The study attempted to finding out the rationale behind nonpursuance of journalism by women. A qualitative survey approach, specifically the key informant interview (KII) approach was adopted. Using the snowball sampling method, 12 women mass communication graduates who were selected for interviews, and their responses were analysed using the thematic approach. The study found that: there was a great deal of perceived discrimination senior colleagues at places of work and by the general society toward women that are into journalism practice in Nigeria; female roles as mothers and wives; religious and cultural beliefs; and poor salary/wages were some of the critical factors impeding women mass communication graduates in Maiduguri from adopting journalism-related careers. The study concluded that women mass communication graduates in Maiduguri have negative perception toward journalism-related careers. The study, therefore, recommended that media organisations should make it as a duty to employ offer employment opportunities to more women and formulate and implement viable and strong gender equality policies.

Keywords: Career consideration, Journalism career, Mass communication graduates, Media organisations, Nigerian news media, Women journalists

DOI: $10.7176 / \mathrm{NMMC} / 98-01$

Publication date:September $30^{\text {th }} 2021$ 


\section{Introduction}

Journalism is as "the mission of collecting, writing and disseminating news and opinions about society through the media". Journalism is a form of communication that is based on asking and answering questions: Who? What? Where? When? Why? How do? Journalists inform the society about itself and publish what would otherwise be private. Journalists also provide information, commentary, and amplification on matters already in the public domain (Ganiyu \& Akinreti, 2011 cited in Tijani-Adenle, 2019).

The emergence of journalism in Nigeria in the mid-19th century was characterised by the predominance of non-professionals, who used their publications to either spread a cause or exchange punches with the colonial authorities. Journalism enterprise began in Nigeria in the early 1960s. At that time, there were only two higher education institutions offering courses in journalism - the University of Nigeria, Nsukka, which started in 1961 and the University of Lagos in 1967. These two institutions offered a diploma in mass communication where students took courses in journalism. According to Emenyeonu (1991) initially, prospective students were reluctant to join journalism because the preferred career options at the time were medicine, engineering, law, and architecture. Nowadays, on the contrary, as there seems to be a fascination in the study of mass communication that is witnessing an exponential rise in the number of candidates (mostly young women), in such a manner that the discipline has become attractive to many Nigerians.

Since the inception of journalism as a speciality field in mass communication studies among Nigerian universities in the 1960s, enrolment has largely been by females until recent years. Studies have even indicated that only a minority of these students choose to work in journalism as a career after graduation. "A clear and burning issue in the Nigeria media today and even in the past is the near absence of female reporters" (Patricia, Samuel, Olufisayo, Evolua \& Umeålio, 2015, p.5). Nigeria, as a developing country, needs both female journalists and their male counterparts to work in media houses. The number of women journalists in the field of journalism is very low compared to the number of graduates who have completed their studies from institutions, journalism schools and universities (Patricia et al., 2015).

Scholars of various disciplines have examined the place of women in journalism through the publications of their disciplines, from historians who document the careers of the pioneers to experts in cultural studies who develop theories about how women use social media (McCluskey, 2011 in Rauhala \& Lindgren, 2012; TijaniAdenle, 2019). Additionally, sociologists and communication scientists have measured the gender gap in newsrooms and researched media promotion of stereotypes. Researchers collected data on content and extracted meaning from clips and videos by counting by-lines or conducting interviews (Oberiri, 2016).

As in many other domains, "the multidisciplinary of journalism scholarship, while enriching, mixes methodologies and confounds efforts to summarize findings and generalise themes" (Rauhala \& Lindgren, 2012, p.19). Many scholars have discovered that there is a high rate of enrolment in journalism as a study rather than as a profession or career. This means that women like to study communication courses in higher education institutions, but do not want to practice it as a career. This may be due to fear, stereotyping, and people's attitude toward women as journalists or even a husband's decision about a journalist (Oberiri, 2016; Patricia et al., 2015; Rauhala \& Lindgren, 2012; Tijani-Adenle, 2019). Hence, this study sought to examine the factors that affect the adoption of journalism as a career among women mass communication graduates in a Northern Nigerian urban centre context.

Journalism is a media profession that offers a variety of career opportunities. Although there are many professional differences in journalism, the ideal goal is to inform the target audience adequately about thematic issues within the community. Journalism serves many useful and vital functions such as informing the public of important facts and events, providing a forum for diverse viewpoints, acting as a guardian of government, institutions, and the public, advocating change in the public interest, and pursuing the truth with an unwavering commitment. What makes a good journalist regardless of career choice is the ability to write excellently, handle a heavy workload and pressure, work experience, diversity of knowledge, and most importantly a nose for news (Ekeli \& Enobakhare, 2013).

Specific career options in journalism include reporting, investigative journalism, photojournalism, columnist, analysts, and the list goes on. Aina (2004, p.210) distinguished some professions in journalism as follows. A reporter is a journalist who searches for some information using research and interviews. Reporters write reports (news stories) about events, issues, and prominent individuals in society. Reporters are also known as correspondents. An investigative journalist is a journalist who provides a more systematic approach to journalism. Investigative journalism requires a "keener news-sense" than traditional news reporting technology. It is also considered one of the most dangerous professions in journalism, as it seeks to ferret out the news behind the news or the big secret the source has vowed to conceal" (Ojomo, 2008, p.17). Some journalists write a column. The term 'column' regarding journalism implicitly denotes the delegation of specific pages of the newspaper to specific topical issues, written regularly over a long time. There are opinion columns, editorial column, sports, business, but just to name a few. Journalists do not write an opinion column. However, with technology, journalists can do so through their blogs and social media platforms. "Columns also allow 
interaction with the reading public" (p.230). Photojournalism involves taking news photos. Photojournalists are professional photographers, unlike other journalists. Photojournalism as defined by Ojomo (2008, p.17) is "telling a story with photographs - reporting with the aid of a picture." The photojournalist is guided by purpose, and this distinguishes his job from other professional photographers. In journalism, there are analysts as well. These journalists work on a variety of rhythms and can be political analysts, entertainment analysts, business analysts, sports analysts, educational analysts, etc.

This study focused on female mass communication graduates only, who were employed in public/governmental or private institutions, or those who previously worked in any of those organisations but who subsequently retired. This was because unemployed female mass communication graduates, or mass communication graduates who did not have any formal organisational work experience were considered unable to provide relevant information about the problem of this study and answer the research questions. This study aimed to examine (1) the factors that affect professional considerations among female mass communication graduates in the city of Maiduguri; and (2) the challenges faced by female mass communication graduates who wish to embrace journalism as a profession in Maiduguri, the capital of Borno State, Nigeria. Hence, this study sought to answer the following research questions (RQ): (RQ1) what are the factors affecting career considerations in journalism among female mass communication graduates in Maiduguri? (RQ2) What are the challenges faced by female mass communication graduates who wish to embrace journalism as a career?

\section{Literature Review}

\subsection{Concept of Gendered Journalism in Nigerian News Media}

t Several researchers have documented that journalistic organisation are highly gendered (Akinfeleye, 2011; Aldridge, 2001; Anyanwu, 2001). This means that gender expectations are deeply rooted in this professional area. The perception of what a man or woman journalist does penetrates the newsrooms on different levels. Gender separation affects the structure, development, and dynamics of journalistic organisations. First, several studies describe the structure of journalism in terms of a deep and horizontal separation of the sexes. Women are severely underrepresented in office, news, and media sectors of high levels of power and prestige (Barton \& Storm, 2014; Byerly, 2014, 2013, 2011, 2004; Dunu, 2015; Tijani-Adenle, 2019). Supporting those claims, Ibrahim, Abba-Aji, Adamu \& Phuong (2021, in press) conclude that,

The atmosphere and culture in the Nigerian news media industry largely portend unsafe experiences, gender-based discrimination and abuses such as sexual harassment, sexism, and gender-based nepotism against women journalists. Nonetheless, although some media organizations ignore the existence of such gender-based abuses as well as discrimination and unsafety in the newsroom to the extent that they expect journalists to protect themselves, other journalists and media management personnel admit the existence of such abuses and discriminations to the extent that they make efforts to control them.

According to De Clercq (2002) "this notion is also reflected in the journalism culture." De Clercq defines organisational culture as a set of (informal) rules that define the work of (workers in) an organisation. These rules are based on the mutual values, symbols, and beliefs that employers consciously or unconsciously adopt and strongly influence their behaviour. De Bruin (1999) notes that these cultural values are often taken for granted, and embodied in norms, norms, and professional career norms. They build relationships, practices, and build a "gendered sub-structure" in the organisation. Over the years, males dominated the journalism profession. Female journalists shy away from practising journalism for many reasons. However, they prefer the more glamorous roles in television, radio, public relations, or advertising over aspects of journalism such as reporting. Moreover, in another study, Bruin attempted to determine mass communication students' perception of the performance of Nigerian women journalists. More than half of the respondents $(55 \%)$ believed that Nigerian female journalists were as good and productive as their male counterparts.

Patricia et al. (2015) conducted a study to find out the perception of female mass communication students regarding career opportunities for women journalists in Nigerian news media if these students were thinking about a career in journalism, the specific career options they might consider and the factor(s) that determine their decision. Employing the investigative research methodology, a sample of 100 female students was randomly selected from a group of 163 female students across levels 100 to 400 at the Redeemers University (RUN). The results revealed that students are not oblivious of the fact that career development of female journalists in Nigeria is challenged by the fact that they do not have the same career opportunities as their male counterparts, and that women's family responsibilities make it more difficult for them to adequately meet the professional expectations required in journalism. Nevertheless, most $(63 \%)$ of the respondents did regard journalism as a good profession for women, with 58\% of them perceiving journalism career positively, especially photojournalism. About half (52\%) of them are interested in journalism, believing that it will provide them with the opportunity to gain diverse knowledge.

Ali (2010) conducted a similar study that focused on the attitude of female mass communication students 
toward journalism as a profession. It is believed that many trained female journalists are trained in various higher institutions in Nigeria, but only a few of them pursue journalistic careers. Hence, the urge for that study. Survey method was employed, which enabled the researcher to draw a sample of 150 respondents. Using a questionnaire and personal interviews, the study surveyed a population that was too large to be personally observed. The study used simple ratios and frequency tables with simple descriptive analysis to explain the tables. Hypotheses formed from the research questions were tested to enable the researcher to provide an understanding of the claims made, which received statistical support. The results of the study revealed that female students of mass communication have a negative attitude toward journalism as a career. The role of women as mothers and wives is also one of the problems facing female journalists. The study recommended the necessity of increasing the salaries of working journalists to motivate and change the negative attitude of mass communication graduates toward journalism as a professional career.

\subsection{Factors Driving Gender Disparity in Journalism}

It has been observed that "traditional cultural attitudes in most societies discriminate against women having access to education" (Ali, 2010, p.37). Moreover, women's lukewarm attitude toward journalism is seen as one of the many reasons that may have encouraged men to claim superiority over women journalists in the Nigerian media industry and, thus, not portray a good image of women in society. Also, men in society believe that exposing women to the cruelty of journalism can make them lose their dignity and value as women, especially in the Nigerian context. Consequently, many female journalists working in media organisations often do not show a keen interest in their jobs, paving the way for their male counterparts to outrun them, both at the office and at work (Aldridge, 2001; Ali, 2010).

Ali stressed that this can also discourage them from practising journalism as young women are encouraged to marry and become housewives or are encouraged to embrace any other work that provides them with ample time to become responsible housewives over the journalism career. There is also an issue of gender bias in the attitude towards women who study journalism or use information technology where many people adopt views that women cannot think or act on scientifically. If they are allowed to work outdoors with men to earn a living, they will forget all about shyness and be interest in pursuing their journalistic career. Women need to demonstrate their invaluable abilities as mothers and housekeepers in jobs like journalism, and they will certainly do better than men. Journalism is a profession for both men and women (Ali, 2010; Okunna, 2005).

Commenting on gender inequality in the media, Okunna's (2005) findings indicate that "the media are male-dominated in terms of subject matter, news, and people who report news, prominence of male and female newsmakers and reporter." Okunna adds that "gender relations in Nigeria are characterized by a lot of imbalances to the disadvantage of women. Tradition, culture, religion, and other factors have continued to widen the disparity between Nigerian men and women, by keeping women in a subordinate position" ( $\mathrm{p} 15)$. In contrast, Emenyeonu's (1991) survey of Nigerian female students carried out to determine their motivations for receiving journalism training found that the number of female students enrolled in journalism training institutions in the country is roughly equal to the number of male students - a factor that should boost women's representation in the media. Moreover, most of the female students surveyed considered journalism as a career suitable for women just as it suits men. However, the scholar suggests marital status as an important factor in career choice - married students said they would quit work if it interfered with their family responsibilities. Also, most respondents tend to prefer more glamorous roles in television, radio, public relations, or advertising over aspects of journalism regarded as rigorous such as reporting. These two factors have important implications for female journalists' career advancements and may continue to exacerbate the underrepresentation of women in Nigerian media institutions.

\subsection{Notable Constraints Faced by Women Journalists}

\subsubsection{Social and Cultural Norms Constraints}

Studies have shown that many issues that present a barrier to female journalists' career development are largely gender related. Okunna (2000) cited in Ali (2010, p.35) notes that "gender relations in Nigeria are characterized by a lot of imbalances to the disadvantaged of women. Tradition, culture, religion, and other factors have continued to widen the disparity between Nigerian men and women whereby women are kept in subordinate positions". Women journalists are often stereotypically placed in less demanding specific tasks or beats. Amao (1999) cited in Ali (2010, p.41) notes that "the female gender is seen as biologically unfit to carry out the tasks that come with being a journalist"; for example, for a long time, female journalists have barely gained traction in areas considered "masculine" such as political analysis, photojournalism, and sports.

Another challenge is the multiple roles and heavy local responsibilities women are expected to fulfil. Uzochkwu (2008) cited in Ali (2010) noted that unlike their male counterparts, women often lack the time to pay attention sufficiently and comprehensively to the expectations of a journalism career. The traditional role of women, especially in Africa, where women are expected to meet the needs of children, do some household 
chores, and provide meals for the family becomes a distraction in journalism, and thus, makes it difficult for female journalists to devote as much time as men do. Ememyeonu (1991) agrees that the lack of adequate representation of women in journalism is partly due to the marital obligations of women that tend to occupy most of the time they would need to devote to their work. Unfortunately, as Palm and Marimbe (2018) noted, very few female journalists reach top management positions throughout their careers.

The issue of sexual harassment is another challenge to women in the press. Female journalists must deal with requests for sexual services from their seniors regardless of their marital status. Scientists in various disciplines have examined the place of women in journalism through the lens of their disciplines, from historians who document the careers of pioneer journalists to experts in cultural development studies who theorize about how women social media (McCluskey, 2011 cited in Rauhala \& Lindgren, 2012). Sociologists and communication scientists have measured the gender gap in newsrooms and examined "media's reinforcement of stereotypes" by the media. Researchers collected data about the content and extracted meaning from clips and videos by continuing by-lines or conducting interviews. "As in so many areas, the multidisciplinary of journalism scholarship, while enriching, mixes methodologies and confounds efforts to summarize findings and generalize themes" (Rauhala \& Lindgren, 2012, p.37).

Most of these scholars have discovered that there is a high rate of enrolment in journalism as a study rather than as a profession. This means that women like to study communication courses in higher education institutions but do not want to practice the profession. This may be due to fear, stereotyping, and people's attitude toward women as journalists or even a husband's decision about women journalists. This notion is supported by Ali (2010) who notes that "discrimination and condition of service make female journalists have negative attitudes towards journalism as a career as well as discrimination by employers also makes female students' journalist have a negative attitude towards journalism as a career" (p.41).

\subsubsection{Vertical Gender Discrimination in Journalism}

The hierarchical separation of positions in journalism is another example of how gender has permeated the structure of the journalism field. Several studies show that the increase in the number of women in journalism has not reached the level of decision-making (Tijani-Adenle, 2019; Unaegbu, 2017). Female journalists are severely underrepresented in positions associated with high levels of power and symbolic capital (Chioma, Okere, Alao, Atakiti \& Jegede, 2015). Moreover, even in countries where there is gender parity in the journalistic workforce, women who can reach higher ranks are an exception (Bayerley, 2013). Numerous studies show that women in journalism face an invisible obstacle that limits their chances of advancement, often referred to as "the glass ceiling" (Ibrahim et al., 2021 in press; Tijani-Adenley, 2019, p.203). This lack of representation of women at the highest levels of media organisations is supported by a wide range of interconnected factors. First, women journalists are often excluded from the informal exchange of professional knowledge and socialisation (Aldridge, 2001). Second, on-the-job training opportunities are unevenly distributed between male and female journalists (Chocarro, 2019). This difference can be traced back to the idea that because female journalists often leave the company or choose to work part-time, the return on investment for media companies when investing in women's training is not guaranteed (Robinson, 2008). This reduces opportunities for female journalists to participate in key learning situations that are critical for career development (Jibril \& Abubakr, 2017).

Moreover, female journalists must address stereotypical thinking patterns about the managerial capacities of men and women (Al-Shamal, 2016). These stereotypes lead to the notion that women are less competent and less suited to leadership positions because they are too sensitive, too sympathetic, or too vulnerable. For example, Njoku, Whyte \& Vincent (2018) and Dunu (2015) use the concept of "friendliness trap" to denote the vicious circle that female journalists must deal with. Upon entering journalism, women are valued for some typical feminine abilities such as seeking dialogue, compatibility, honesty, and sensitivity. However, these characteristics are often interpreted as poor leadership capabilities. In decision-making positions, male characteristics such as competition and firmness are usually evaluated more. Moreover, several studies indicate that women who reach the next level face some additional forms of sexism. For example, they must deal with constant pressure to succeed or to adapt male management styles and priorities (Njoku et al., 2018), or be suspected of favouring other female journalists (Tijani-Adenle, 2019) or become passive and sexist reactions from male co-workers (Burley, 2013).

\subsubsection{Horizontal Gender Discrimination in Journalism}

Past studies indicate that the field of journalism is also horizontally segregated and characterised by a gender division of news areas and media sectors (North, 2016; Unaegbu, 2017). Female journalists are overrepresented in traditional "softer" female news domains and media sectors with low levels of prestige such as human interest, lifestyle, and fashion news. On one hand, men outnumber women in difficult news reports such as political news, financial news, and crime news. Several scholars note that this gender division between serious and soft news 
reflects the dichotomy between the public sphere and the private sphere in the social system (Dumatop, 1988; Nort, 2016; Tijani-Adenle, 2019). Male-dominated serious news beats are associated with the prestige and the role of censorship of the press in a democracy and the public sphere as defined by Habermas in Unaegbu (2017); whereas women are traditionally confined to the private sphere, and therefore, they are more active in the pleasant news rhythms that correspond to their household tasks (North, 2016). However, although these divisions are evident, many journalists believe that journalism is gender-neutral and avoid discussing the existence of a gender division of news topics (Bayerley, 2013). Also, the participation of women journalists is linked to the prestige of the media sector. Less well-known media sectors are more accessible to women journalists than prominent media sectors. North (2016) explains this based on the example of the radio sector. She describes how opportunities for women in the broadcasting sector have increased because the medium's status is deteriorating with the increase in popularity of television. On the other hand, according to Creedon's (1993) velvet ghetto thesis cited in Tijani-Adenle (2019), the increase of female journalists in the media sector will be accompanied by a decrease in stature and salaries.

The vertical segregation of positions in journalism is another example of how gender permeates the structure of the field of journalism. Numerous studies demonstrate that the increase in women in journalism has not reached the decision-making level (Tijani-Adenle, 2019; Unaegbu, 2017). Female journalists are strongly underrepresented in positions that are associated with high levels of power and symbolic capital (Chioma, Okere, Alao, Atakiti \& Jegede, 2015). Moreover, even in countries where there is gender parity in the journalistic workforce, women who can make it to the top level are an exception (Byerly, 2013). Several studies show that women in journalism face an invisible barrier that limits their chances for advancement often referred to as the glass ceiling (Ibrahim, Abba-Aji, Adamu \& Phuong, in press; Tijani-Adenle, 2019). This underrepresentation of women at the top level of media organizations is sustained by a wide range of interrelated factors. Firstly, female journalists are often excluded from the informal exchange of professional knowledge and socialization in the old boys' network (Aldridge, 2001). Secondly, opportunities for on-the-job training are unequally distributed between male and female journalists (Chocarro, 2019). This difference can be brought back to the idea that, since female journalists often leave the company or choose to work part-time, the return on investment for the media companies when investing in training for women is not guaranteed (Robinson, 2008). This reduces the chances for female journalists to participate in key learning situations that are crucial for career development (Jibril \& Abubakar, 2017).

Furthermore, female journalists must deal with stereotypical thought patterns about the management capacities of men and women (North, 2016). These stereotypes result in the idea that women are less competent and less suitable for leadership positions because they are too sensitive, too empathic, or too soft. Njoku, Whyte \& Vincent (2018) and Dunu (2015), for example, used the concept of the 'friendliness trap' to refer to the vicious circle that female journalists must deal with. When they enter journalism, women are appreciated because of certain typically female capacities such as aiming for dialogue and consensus, honesty, and sensitivity. However, these characteristics have often been interpreted as bad leadership capacities. In decision-making positions, typically male characteristics such as competition and assertiveness are valued more. Furthermore, numerous studies indicate that women who do make it to the top level, face some additional forms of gender bias. For example, they must deal with a constant pressure to succeed or to adapt masculine management styles and priorities (Njoku et al., 2018), they are suspected of favoring other female journalists (Tijani-Adenle, 2019) or they get negative, sexist reactions from male co-workers (Byerly, 2013).

Against this background, this study sought to know the factors that affect the adoption of journalism as a profession by female mass communication graduates.

\subsection{Theoretical Framework}

To clarify the various issues related to female mass communication graduates adopting the practice of journalism as a behavioural practice (profession or profession), this study used the Theory of Planned Behaviour (TPB) as a framework.

\subsubsection{The Theory of Planned Behaviour}

According to Icek Ajzen (1991), the theory states that attitude toward behaviour, subjective norms and perceived behavioural control combine to form an individual's behavioural intentions and behaviours. The concept was proposed by Icek Ajzen to improve upon the predictive power of the Theory of Reasoned Action by incorporating perceived behavioural control construct. This construct has been applied to studies on the relationships between beliefs, attitudes, behavioural intentions, and behaviours in various fields such as advertising, public relations, advertising campaigns, healthcare, sports management, and sustainability. The Theory of Planned Behaviour was proposed by Icek Ajzen in 1985 through his paper "From intentions to actions: A theory of planned behaviour". The theory was developed from the Theory of Reasoned Action, which was proposed by Martin Fishbein with Icek Ajzen in 1980. According to the Theory of Reasoned Action, if people 
"evaluate" the proposed behaviour as positive (attitude) and if they think that their significant others want them to perform the behaviour (subjective norm), then this leads to a higher intention (motivation) and they are more likely to do so. The high correlation between attitudes and subjective norms to behavioural intention, and subsequently to behaviour, has been confirmed in several studies.

\section{Methods}

\subsection{Research Design}

This study adopted a qualitative survey approach. Specifically, the key informant interview (KII) approach was adopted. According to Marshall (1996), a key informant is an expert source of information. The key informant technique is an ethnographic research method which was originally used in the field of cultural anthropology and is now being used more widely in other branches of social science investigation.

\subsection{Subjects of the Study}

The subject for this study consisted of all female mass communication graduates in Maiduguri, Borno State. After the target study subjects have been defined, the next step is to decide how to enroll subjects in the study. This starts with determining the target subject population. However, statistics on the number of female mass communication graduates in Maiduguri metropolis was not obtainable; hence the population size could not be determined. Nonetheless, in the actual study, the sample used for the research project contains only the individual subjects who will participate in the study. In other words, of the overall population, the sample contains only a small portion of the target population, which is selected for analysis. How this sample is selected from the entire population of subjects can impact the quality of the study (Patton, 2015).

Of the total of 12 participants selected for key informant interviews, eight were not pursuing journalism or mass communication-related careers while the remaining four were. The ages of the participants who did not pursue journalism-related careers ranged between 42 and 55 while the age range for those that pursued journalism-related careers was between 33 and 44 years. All the 12 participants are women graduates of mass communication and lived in various areas in Maiduguri metropolis during the data collection time. Three of the participants that did not pursue journalism-related careers were working as entrepreneurs while the remaining five were pursuing careers in banking $(n=2)$, telecom services $(n=1)$ and civil service $(n=3)$. While both the participants who pursued journalism-related careers were working in different broadcast media organizations $-\mathrm{a}$ Television news reporter and a radio program producer.

\subsection{Sample Size and Sampling Technique}

Because this study adopted a qualitative, key informant interview approach, only 12 female mass communication graduates were interviewed in-depth (see Marshall, 1996). According to Liamputtong and Ezzy (2005), a sample size refers to the population that is being used for research. Furthermore, due to the research design adopted and the nature of the study, snowball sampling was adopted. Snowballing sampling is a process in which the first subjects are drawn by convenience and these subjects then recruit people they know to participate, and they recruit people they know, etc. (Bailey, 2008).

\subsection{Participant Coding}

To simplify data analysis and coding as well as themes identification, a code was designed to identify each participant in the results (see Ibrahim et al., in press; Tijani-Adenle, 2019, p.95). Since the interviewees' names and identities were concealed, the data used to design the codes were based on each participant's career as to whether it was related or not related to journalism and/or mass communication followed by a serial number the researchers assigned to each participant serially. Thus, participants pursuing journalism and/or mass communication-related careers were coded as Participant $C R-J \& M C-n$ where $\mathrm{CR}=$ career, $\mathrm{J}=$ journalism, $\mathrm{MC}$ $=$ mass communication, and $\mathrm{n}=\mathrm{a}$ serial number (e.g., Participant CR-J\&MC-01); whereas, participants who were not pursuing a journalism and/or mass communication-related careers were coded as Participant NCR$J \& M C$ - $n$ where NCR = non-career, while the full meaning of J\&MC-n is already defined previously (e.g., Participant NCR-J\&MC-11).

\subsection{The Instrument for Data Collection}

For this study, given that the study is a qualitative interview approach, a question guide was designed. The question guide was designed based on the theoretical framework of this study, i.e., the Theory of Planned Behavior. Two separate question guides were designed to collect data from the two categories of the participants, namely female mass communication graduates who were pursuing a career in related to journalism and mass communication (e.g., broadcasters, information officers, etc.) and female mass communication graduates who were not pursuing any profession related to mass communication or journalism. Each of the question guides contained nine open-ended questions. The questions were designed to elicit in-depth responses to the research 
questions put to the key informants (Rahman, 2015). Each participant was pre-informed of the interview and a request letter was given to them. The researcher visited each participant based on the time and venue scheduled (rendezvous). During the interview, the researcher disabled all mobile and internet communication features of the smartphone used to prevent interruptions by an incoming call, text messages and or internet services. Each interview was saved with a separate name for easy recognition during transcription. All the interviews were then transcribed one after the other and then analyzed accordingly.

\subsection{Method of Data Analysis}

Data for this study were analyzed using interviews collected from the response given by the respondents and was presented in a discussion format. Thematic data analysis was used to analyze the data based on the existing themes available in extant literature. This was to provide a basis for situating the factors in the media industry circumstance (Ali, 2013). All the interviews were recorded using a nicely working smartphone.

\section{Results and Discussion}

The responses of the women graduate of mass communication in Maiduguri metropolis who did not pursue careers related to mass communication or journalism are presented and analyzed in the paragraphs that follow. The data are simultaneously presented and discussed thematically considering challenges and driving factors of journalism career consideration among women. The participants were aged 33 to 55 years with those not pursuing journalism-related careers older than their counterparts who were pursuing journalism-related careers.

\subsection{Socio-Cultural Challenges Affecting Journalism Career Consideration among Women Graduates of Mass Communication}

Having studied mass communication as a course at an advanced or degree level, and in a university, ordinarily, pursuing a career that is related to media or journalism, even temporarily, would be a nice idea to them. Most of the Participants NCR-J\&MC-01 to 08 and Participants CR-J\&MC-01 and 02 admitted that journalism or mass communication-related career would be nice to undertake as Participant NCR-J\&MC-01 puts it, "Mass communication is a good and professional course", however, all of them indicated that journalism profession as far as women are concerned, is full of daunting challenges and frustrations and that even "studying it [mass communication/journalism] is not easy" according to as Participant NCR-J\&MC-07 who insists that for her, as a lady, practicing journalism would not be "a good idea because of the challenges and risk associated with it." However, given that they are graduates of mass communication, they possibly may have graduated with flying colors; should that be the case, many people who were important to them, for example, their families, parents, friends, and mentors would naturally expect that they pursue a career that is related to mass communication and journalism. Similarly, most of them responded affirmatively, with one of them adding that,

When I was studying, my parent and family members were happy and expected that I would be seen on the television screen as a presenter or newscaster someday, whenever they tune into a program and listen to me anchoring it. I know they would be so happy. But, for me, personally, I don't consider journalism or mass communication-related career as something I would venture into. (Participant NCR-J\&MC-09)

However, aside of the people who are most important to them, as mentioned earlier, probably, even most other people who have known them personally and have known that they are graduates of mass communication would naturally expect them to undertake careers related to what they studied at a degree level in a university. Not everyone would agree, though. However, as Participant CR-J\&MC-02 admitted that her family, friends, and neighbors appreciated the fact that she studied mass communication and were happy to see her pursue a journalism-related career and that they did not push her to join journalism, "my personal interest did" she says; Participant NCR-J\&MC-09 says,

As I stated earlier, many people have expected that I will work in journalism or media-related career but then every individual has the right to make a personal decision and pursue his or her personal interests, too. So, the fact that people are expecting much from me by seeing me on TV or listening to my voice on the radio or reading my reports in newspapers as a practicing journalist won't change my decision.

Because of the wealth of experience, the participants may have gathered over the years, right from the time they were studying as undergraduates of mass communication to the present time when they are pursuing various careers of their choice and interest; they might have possibly got several friends of theirs who are pursuing mass communication and/or journalism-related careers whether as freelancers or otherwise such as media journalism/news reporting, broadcasting, public relations, advertisement, TV acting, and so on. Probably, they should naturally have the confidence to pursue or to have pursued a journalism and/or mass communicationrelated career. Responses of various shades and colors would naturally be expected from the participants as one of them bares her mind thus: 
Initially, before I got admission to study the course [mass communication/journalism], I had already made up my mind to become a newscaster. But after coming and having passed through the system, I realized that mass communication is a whole lot of business on its own. After being taught about the risks associated with practicing journalism, I decided not to go for it. (Participant NCR-J\&MC-03)

As for Participants NCR-J\&MC-06, 02 and 05, they were not afraid of joining journalism as a career because of the impending risks in it, rather because of the factors driving the adoption of journalism or "any mass communication-related career" as Participant NCR-J\&MC-02 cries. According to them, all the ups and downs being widely talked about and those that are being experienced by those women who are already in the job will rather groom them to develop a thick skin to cope with the challenges because, as Participant NCRJ\&MC-05 notes, "she will be able to stand out wherever she finds herself." While Participant NCR-J\&MC-02 submits that,

Risks will usually come and go; they aren't gonna be permanent. In fact, as it is now, most women journalists or media-related career women do face mountains of challenges. But if the challenges persist, one can quit and join another suitable or fairly suitable job.

In addition to having discussed the various factors affecting women graduates of mass communication and journalism from considering journalism as a career, many of them admitted that an individual's intention can also be considered as a key factor. As stated earlier, at first, one might have had the passion to practice journalism "but later on, one might lose interest and drop the idea, not because of anything but because she or he now doesn't have the passion for the career and gives up the intention" according to Participant NCR-J\&MC-04. "Sometimes our past experiences influence our decisions," says Participant CR-J\&MC-01, who was already pursuing a career in journalism, though. She further explains that "but if you have the passion and the intention to become a journalist maybe someone inspired you, for example, nothing can stop you from realizing your dream. That's exactly how I did." Admitting, Participants CR-J\&MC-02 says

This can be true. In the past, an individual might have had some personal experiences or got wind of experiences of somebody close to them that could make them not to desire to pursue a career in a media-related profession despite being a graduate of mass communication. Please comment. I remember a distant relative of mine experienced such as thing many years before I even knew I would study mass communication. But she later got a pat on the back and joined the profession in which she grew through the ranks to become an editorial manager through thick and thin. I think I was inspired by her courage and determination. That's why closed my eyes, shunned all the negative stories being peddled around that journalism is not for women and joined the career. Now I'm doing quite well. But I cannot say I don't face challenges. In fact, in many instances, I had blamed myself for joining this career. But when I remember that life itself is a challenge and remember my role models in that I watched cast news on NTA Network News long time ago such as Eugenia Abu, Aisha Katung, Mary Adam, Fatima Abbas Hassan, and recently such as Jummai Yusuf, Ienre John, Becky Modujemo and so on I feel excited and motivated. These are Nigerian women like me. If I keep seeking after comfort zones, I won't make any real progress in life. But I still say, mountains of challenges are littered all over the path.

Often, some factors, circumstances or challenges would make it difficult for an individual woman graduate of mass communication and journalism to consider a career in journalism and mass communication-related profession. The way journalism is portrayed by others "can make one flee and give up the dream of wanting to join it no matter what the good side of it might be" says Participant NCR-J\&MC-01. While Participant NCRJ\&MC-08 counter argues her, saying that,

Sometimes, the way women are portrayed by the media, for example, as sex objects, as commodities, as things for pleasure-seeking such as in adverts displaying their nudity-all these is disgusting to me. This is so disgusting especially because of my religious and cultural background - which I cannot disown no matter what... Decency is an asset; it can't be acquired by the display of nudity on national TV or in the pages of newspapers, magazines or on the sites of online media. Much as I want to practice what I studied at university, I also want to live a decent, morally responsible life... unfortunately, in my opinion, I don't see that in journalism or media job. Hence, one of the reasons I shunned practicing what I studied at university. Apart from this, journalism is a noble profession.

\subsection{Political, Professional and Administrative Factors Affecting Journalism Career Consideration among Women Graduates of Mass Communication}

Many of the participants, both those pursuing and those not pursuing journalism and/or mass communicationrelated career, specifically Participants CR-J\&MC-01 and 02 and Participants NCR-J\&MC-06, 02 and 05 respectively identified some of the critical factors affecting or hindering journalism career consideration among 
women graduates of mass communication as including social, cultural, religious, political, and professional. According to the social, cultural and religious factors include "the general perception of the society toward women journalists or women working in the media industry" as Participant NCR-J\&MC-05 notes (e.g., many of them are being stigmatized as men-like, competing with men, not able to lead a good married life, not able to raise children properly, not religiously and morally responsible, leading promiscuous lifestyles, vulnerable to HIV infection, and so on). Whereas some of the key political factors include political influence, commercial and economic or profit interests and male domination of the Nigerian media industry. These factors agree with Sarikakis (2014, p.66) who puts it as "Power, patriarchy and profit"” while Tijani-Adenle (2016, p.397) admits that that "remains the 'powerful triangle' preventing the advancement of women in journalism" (Tijani-Adenle, 2019, p.98).

Regarding the professional factors, according to the participants, these include the lack of media industry gender-related policy in and disorganized structure of the industry as well as the status of women in typical Nigerian society, a phenomena Tijani-Adenle (2019) describes as "the place of women in the Nigerian society" (p.90). These submissions are further supported by North (2009) and Anyanwu (2001). Another key factor is as identified by most of the participants is gender-based and sexual harassment women journalists and media practitioners experience at work. This factor has been well-researched, and many previous studies agree with these participants' opinion (see Ibrahim et al., in press; Sebba, 1994; Tijani-Adenle, 2019, 2016, 2014; TijaniAdenle \& Oso, 2014).

The study also revealed that the participants have a negative attitude towards journalism as a career. This implies that they prefer to go into other endeavors of life after graduation than to practice journalism as a career. They would prefer teaching, private business, modelling, artist than choosing journalism as a career. The findings also show that despite most of the participants did agree that journalism is a good profession, many of them did not pursue it as a career after graduation, implying that journalism is not seen as a woman-suitable career in Maiduguri metropolis. This is largely due to the risks and gender-based discriminations involve journalism practice as revealed by the participants.

The study also identified religious beliefs, culture, and discrimination contributes greatly to dissuade women from choosing journalism as a career. These findings are per what Ali (2010) submits that "traditional cultural attitudes in most societies also discriminate against women having access to education". This can also discourage them in the practice of journalism as young women are encouraged to get married and become housewives or encouraged to take up any other job which gives them more time and makes them responsible housewives than their journalism profession. There is also the issue of gender bias in attitude towards women studying journalism because many people hold the views that women cannot think or work scientifically.

The findings further revealed that there are low percentages of women in the journalism profession even though there is a high enrollment of female in journalism classes. These findings are in line with Okunna (2005) which reveals that "the media are male-dominated in terms of subject matter, news, and people who report news, prominence of male and female newsmakers and reporters". Okunna (2005) adds that "gender relations in Nigeria are characterized by a lot of imbalances to the disadvantage of women. Tradition, culture, religion, and other factors have continued to widen the disparity between Nigerian men and women, by keeping women in subordinate positions."

\section{Conclusion}

The ingenuity, intelligence and creativity that trained Nigerian women mass communication and/or journalism graduates can offer to the news media industry should they consider journalism as a professional career after graduation could be tremendously valuable. However, poor management, daunting socio-cultural norms, maledominated newsroom culture, poor remuneration, profit, patriarchy, power, gendered journalism culture, marriage and work norms continue to portray journalism career in a bad light in the society, which negatively affects women mass communication and/or journalism graduates' career consideration for journalism. This can be worsened by the fact that few women journalists can break into positions of editorial influence in the newsroom because most women journalists working for Nigerian news organisations suffer from one inequality or another. These culminate to discourage women journalism graduates to consider journalism as a professional career; rather they often opt to pursue mass communication and/or journalism studies and embrace more appealing, less 'stereotyped' career after graduation. It is hoped that the results presented in this paper will provide more evidence to support existing literature and encourage the Nigerian news media to revolutionise the industry to meet global standards. This can help launder the perceived bad image of the industry regarding the woman journalism career pursuant.

In reversing the discrimination of a female journalist, the study reveals that lectures and seminars should be made to enable the masses to know the inherent value of a female journalist in society. The perception of women seen as weaker vessels should be changed. Masses should be enlightened on the roles both genders can play to sustain gender equality. This finding is in line with Ali (2010), where she submits that "if the women can be 
allowed to share outdoor work with the men to earn a living, they will forget everything about shyness and have the interest in practicing their Journalism profession. Women need to demonstrate their priceless abilities as mothers and managers of the home in such careers as journalism, and surely, they would do better than our men folks. Journalism is a profession for both men and women. Nigerian women should see journalism as natural intelligence and sense of perfection which natural endowments are and from God himself to women.

\section{References}

Aina, S. (2004). Intermediate Newswriting and Reporting. Abeokuta: Julian Publishers.

Ajzen, I. (1991). From intentions to actions: A theory of planned behaviour. In J. Kuhl \& J. Beckman (Eds.), Action-control: From cognition to behaviour (pp. 11-39). Heidelberg: Springer.

Ajzen, I. (1985). The theory of planned behaviour. Organisational Behaviour and Human Decision Processes, $50,179-211$.

Akinfeleye, R. (2011). Essentials of journalism: an introductory text. Lagos: Malthouse Press Limited.

Aldridge, M. (2001). Lost expectations? Women journalists and the fall-out from the 'Toronto newspaper war'. Media, Culture and Society, 23(5), 607-624.

Ali, M. \& Ching, L. L. (2013). Using the key informants interviews (KIIs) technique: A social sciences study with Malaysian and Pakistani respondents. Man and Society, 24, 131-148.

Ali, I. E. (2010). The attitude of female mass communication students towards journalism as a career. In Nnamdi Azikwe University, Awka, Southwestern Mass Communication Journal, 1, 14-41.

Anyanwu, C. (2001). In Nigerian newspapers, women are seen, not heard. Nieman Reports, 55(4), 68-71.

Bailey, K. (2008). Methods of social science research (4th ed.). New York: The Free Press.

Byerly, C. (2014). The long struggle of women in news. In A. Montiel (Ed.), Media and Gender: A scholarly agenda for the global alliance on media and gender (pp. 34-36). France: UNESCO and IAMCR.

Byerly, C. (ed.) (2013). The Palgrave international handbook of women and journalism. Hampshire, Palgrave Macmillan CA: Sage.

Byerly, C. (2011). Global report on the status of women in the news media. Washington: International Women Media Foundation.

Byerly, C. (2004) Feminist interventions in newsrooms. In K. Ross \& Byerly, C. (Eds.), Women and media: international perspectives (pp. 109-131). MA: Blackwell.

Creedon, P. M. (1993). The challenge of re-visioning gender values. In P. M. Creedon (Ed.), Woman in mass communication (2nd ed.), (pp. 3-23). Newbury Park, California: Sage Publications.

Chioma, P. E., Okere, S., Alao, O. O., Atakiti, I. O., \& Jegede, O. O. (2015). Career considerations in journalism among female mass communication students of Redeemers University. Research on Humanities and Social Sciences, 5(14), 2225-0484.

Chocarro, S. (2019). The safety of women journalists: Breaking the cycle of silence and violence. Copenhagen: International Media Support (IMS) Book Series.

De Bruin, M. (1999). Gender, media production and output. Media Development, 46(2), 50-54.

De Clercq, M. (2002). Shedding light on absence: Women's underrepresentation in the newsroom. In Proceedings of the $23^{r d}$ conference and general assembly of the IAMCR, July 21-26, 2002, Barcelona, Spain.

Dunu, I. V. (2015). Media handling of gender issues in contemporary Nigerian conflicts. A paper presented for international press centre for experts' meeting on media and emerging issues in conflict in Nigeria, 11th March 2015.

Ekeli, O. E. \& Enobakhare, U. J. (2013). Social media and the changing nature of journalism practice in Nigeria. In D. Wilson, (Ed.), Communication and the new media in Nigeria (pp. 121-127). Lagos: ACCE Nigeria Chapter.

Emenyeonu, N. B. (1991). Motivations for choice of course and career preferences of Nigerian female students: Implications for the status of media women in a developing nation. African Media Review, 5(2), 71-82.

Ferri, A. J. \& Keller, J. E. (1986). Perceived career barriers for female television news anchors. Journalism Quarterly, 63, 463-467.

Ibrahim, A. A., Abba-Aji, N., Adamu, M. A. \& Phuong, V. T. (in press). The safety of women journalists in Nigerian news media: Exposing the hushed gender-based discriminations. In S. Jamil, Coban, B., Ataman, B. \& Appiah-Adjei, G. (Eds.), Discrimination, gender disparity and safety risks in journalism (No.: 080420-082021). Hershey, PA: IGI global. doi: 10.4018-978-1-7998-6686-2

Jibril, A. \& Abubakar, A. (2017). Public perception of female journalists in North-East Nigeria. Journal of Communication and Media Research, 9(2), 108-119.

Liamputtong, P. and Ezzy, D. (2005) Qualitative research methods. 2nd ed. Melbourne, Victoria: Oxford.

Marshall, M. N. (1996). The key informant technique. Family Practice, 13(1), 92-97.

North, L. (2016). The gender of 'soft' and 'hard' news: Female journalists' views on gendered story allocations. 
Journalism Studies, 17(3), 356-373.

North, L. (2009). The gendered newsroom: how journalists experience the changing world of media. Cresskill, NJ: Hampton Press.

Oberiri, A. D. (2016). Career considerations in journalism among female mass communication students of Taraba State University. World Scientific News, 57, 13-22.

Ojomo, O. W. (2008). Introductory photography and photojournalism. Lagos: Coronate Books.

Okunna, C. S. (2005), Women as invisible as ever in Nigeria's news media. International Journal of Media and Cultural Politics, 1(1), 1-20.

Palm, M. \& Marimbe, S. (2018). Women in media: Fighting trolls, norms and the occasional bully. In Paving the way for good journalism (pp. 27-31). International Media Support Annual Report.

Patton, M. Q. (2015). Qualitative research and evaluation methods: Integrating theory and practice, 4th ed. London: Sage.

Patricia E. C., Samuel O., Oluwafisayo O. A, Ifeoluwa O. A, Omolayo O. J. (2015). Career considerations in journalism among female mass communication students of Redeemers University. Research on Humanities and Social Sciences, 5(14), 1-8.

Rahman, S. (2015). Ethical issues of fair subject selection in the research. Bangladesh Journal of Bioethics, 6(3), 37-40.

Rauhala, A. Lindgren, A., \& Fatima, S. (2012). Women in the Field: What do you know? A snapshot of women in Canadian journalism. New York: Ryerson Journalism Research Centre.

Reep, D. \& Drambrot, F. (1987). Television's professional women: Working with Men in the 1980’s. Journalism Quarterly, 64, 345-370.

Sarikakis, K. (2014). Power, patriarchy and profit: barriers to gender mainstreaming in media policy. In A. Montiel (Ed.), Media and gender: a scholarly agenda for the global alliance on media and gender (pp. 6669). France: UNESCO and IAMCR.

Sebba, A. (1994). Battling for news: Rise of the woman reporter. London: Hodder and Stoughton.

Sobowale, I. (1985). Historical development of the Nigerian press. In F. Ugboajah (Ed.), Mass communication, culture and society in West Africa (pp. 27-35). London: Hana Zell Publisher.

Tijani-Adenle, G. (2019). Women in Nigerian news media: Status, experiences and structures, (unpublished doctoral thesis), De Montfort University, Leicester, the United Kingdom.

Tijani-Adenle, G. (2016). She's homely, beautiful and then, hardworking! Critiquing the representation of women leaders and managers in the Nigerian press. Gender in Management: An International Journal, $31(5 / 6), 396-410$.

Tijani-Adenle, G. (2014). Women and journalism. Gender and Development, 22(2), 389-391.

Tijani-Adenle, G. \& Oso, L. (2014). Muted gender: How Nigerian press portrays femocrats. In O. Omojola (Ed.), Women's political visibility and media access: The case of Nigeria (pp. 89-108). Newcastle, UK: Cambridge Scholars Publishing.

Unaegbu, L. N. (2015). Safety Concerns in the Nigerian Media What gender dynamics? In U. Carlsson \& R. Poyhtari (Eds.), The assault on journalism: Building knowledge to protect freedom (pp. 171-184). Sweden: NORDICOM University of Gothenburg. 